\title{
La Casa de Hacienda de Shuracpamba: visión arquitectónica desde el análisis estratigráfico
}

\section{The colonial farm house of Shuracpamba: an architectural from a stratigraphic analysis}

\author{
María del Cisne Aguirre Ullauri \\ Doctoranda por la Universidad Politécnica de Madrid \\ Docente de la Universidad Católica de Cuenca. Ecuador \\ e-mail: cisne2222@hotmail.com, maguirreu@ucacue.edu.ec
}

\section{RESUMEN}

Shuracpamba, una de las históricas haciendas del Sur del Ecuador, ha permanecido prácticamente en el anonimato. Pretendiendo difundir algunas de las singularidades de este conjunto arquitectónico, se desarrollaron las tareas de búsqueda documental y reconocimiento in situ de la casa de hacienda conservada. El construir su secuencia histórica, e histórica-constructiva, a la par de atar algunos vínculos sociales y culturales históricos, hacen de esta investigación uno de los escasos textos que abordan al objeto y algunas de sus múltiples dimensiones, aunque parcialmente. Particularmente, es el primero en ensayar el método de análisis estratigráfico constructivo, evidenciando cinco campañas edificatorias, materiales y técnicas utilizados.

Palabras clave: Lectura de paramentos; método estratigráfico; Shuracpamba; Hacienda; materiales históricos.

\section{ABSTRACT}

Shuracpamba, a colonial farm located in southern Ecuador, has remained in anonimity. With the aim of making some of the particularities of this architectural complex; tasks such as bibiliographic research and in situ recognition of the preserved building have been carried out. This research is one of the few texts that addresses the object and some of its multiple dimensions, although partially, by constructing its historical and historical-constructive sequence, and tying them in with some social and historical connections. Additionally, this is the first research to test the statigraphic constructive methodological analysis by evidencing five building campaigns, materials and techniques used.

Keywords: Wall surface interpretation; stratigraphic method; Shuracpamba; colonial farm; heritage materials.

Recibido: 04-07-2016. Aceptado: 07-10-2016.

\section{Copyright}

(c) 2016 CSIC. Este es un artículo de acceso abierto distribuido bajo los términos de una licencia de uso y distribución Creative Commons Attribution (CC-by) España 3.0 . 


\section{INTRODUCCIÓN}

A mediados del XX, la Ley de Reforma Agraria y Colonización de 1964 trastocaron de fondo y forma las estructuras latifundistas del Ecuador. En el caso del territorio meridional, los vestigios materiales y culturales de ejemplos singulares como la Hacienda de Shuracpamba ${ }^{1}$, Susudel, El Paso, El Tablón, etc., son aún visibles, en mayor o menor medida. De ellas, quizá las que conservan mayor integridad arquitectónica son las dos primeras, aunque su situación no deja de ser desoladora. Ambas vinculadas al medio natural, hitos potentes del territorio, el paisaje, la estructura urbana y el imaginario local. Shuracpamba, en especial, se caracteriza por la activa presencia social y práctica en instancias concretas de la Medicina Natural y Ancestral, así como por sus históricos propietarios, las familias Serrano Coronel de Mora y Valdivieso².

Esta realidad da lugar a un rico legado construido desde la convivencia histórica y material, haciendo del sitio y los elementos característicos, un conjunto de interés integral que bien valdría abordar ampliamente desde otras disciplinas. En adelante y por los propios intereses del presente, se desarrolla concretamente el elemento principal del complejo arquitectónico y su relación con algunas dimensiones a él asociadas, ya que otros aún existentes muestran en primer caso un elevado estado de deterioro, y en el otro, una presencia temporal sin representatividad histórica (Fig. 1). A través del método de análisis estratigráfico constructivo ${ }^{3}$, con asistencia de las fuentes escritas y gráficas identificadas, más la acotación de información de relevancia se identifican las cinco transformaciones producidas entre 1773 y la actualidad, fruto del paso del tiempo, la limitada gestión monumental, así como la incidencia de las condiciones viales, la propia ubicación y distancia ${ }^{4}$ a los asentamientos más cercanos.

1. Sobre el nombre, existente textos que la identifican como Zhuracpamba, Shuragpamba o Zhuragpamba. La definición de toponimia y correcta escritura, deberá ser objeto de otro estudio.

2. Estas familias son de los típicos núcleos pudientes del Sur del país. La primera desde el siglo XVI, y la segunda que durante el siglo XIX conformaron la clase dominante cuya hegemonía se mantuvo por la ratificación de vínculos con otras familias del mismo estrato. Para ampliar información ver Palomeque (1990).

3. Término utilizado por Camilla Mileto y Fernando Vegas (2003) con referencia a las aportaciones de Luis Caballero Zoreda (1995), en relación a la discusión terminológica sobre el método. Otras acepciones referenciales serían lectura de paramentos, lectura estratigráfica muraria, análisis estratigráfico murario, entre otros.

4. Al respecto de la ubicación exacta, el Acuerdo No. 010-2013 para la Declaratoria como Patrimonio Cultural de la Nación, la determina con precisión técnica a través del código BI-01-10-51-000-000001A.

\section{ANTECEDENTES}

Entre los anónimos de la región se encuentra la hacienda de Shuracpamba, sobre ella y por la documentación más abundante, la secundaria, se sabe que al igual que la Hacienda de Susudel ${ }^{5}$, son a día de hoy constantes de interés en el diseño, oferta y demanda de planes turísticos y deportivos. La referencia a su pasado histórico nativo y colonial, lo promueven (Maldonado 2009: 9), así como las características intrínsecas de su territorio, y en los últimos años, el avistamiento de algunos ejemplares de cóndor ${ }^{6}$, ave insignia del Ecuador. En el territorio destaca la transición entre la ocupación cañari, inca y española en la zona, por hablar de las más recientes ${ }^{7}$, o datos generales sobre sus propietarios históricos, como el caso de Maldonado (2009) y Ortega (2015).

De investigaciones, como Nudos de poder y familias encadenas de frontera ${ }^{8}$, desarrollada por Marcia Stacey (2007) y El Paso: Una Hacienda Tradicional en la Sierra Centro -Sur del Ecuador ${ }^{9}$ de Manuel Carrasco (2012), es posible deducir características afines y relaciones entre las haciendas de El Paso, Susudel y Shuracpamba. Se sabe que su origen, proveniente de la merced de tierras, requerimiento efectuado por españoles y/o sus descendientes ante la Audiencia y Virreinatos (siglo XVI), con intereses económicos en torno a la producción, agrícola-ganadera o minera. Stacey (2007) en oposición a Espinoza (2012) afirma que estas estructuras tenían enormes extensiones, superando los miles de hectáreas, aunque no siempre productivas por su calidad y/o escarpada topografía. Según Valdivieso (2016a), la relación productividad-extensión territorial, no era directa, y se veía afectada - aún hoy — por la ausencia de carreteras, su elevado estado de deterioro, el fatigoso trabajo para la obtención de recursos y lo elemental de los medios de explotación (Stacey 2007: 12; Espinoza 2012). Aun así, Stacey (2007: 14-18) detalla una amplia variedad de productos, tanto de entrada como de salida,

\footnotetext{
5. Por su cercanía geográfica frecuentemente se incluyen ambas en los itinerarios.

6. Desde el año 2014 el Gobierno Municipal de Oña, ente de gestión y administración territorial, se ha planteado como Eje Cultural de Desarrollo Local, la gestión de la Declaratoria de Área Protegida Municipal, a las zonas de Shuracpamba y el río León, por ser hábitat de dicha especie. (Ullauri 2014) 7. Investigaciones realizadas por Matilde Temme Witt desde 1977, en la zona de Oña y cercanías, muestran evidencia de asentamientos del año 7000 a. C., aproximadamente (Marca 2011).

8. Para ampliar ver http://myslide.es/documents/hacienda-el-tablon-de-ona. html, recuperado el 27/03/2016.

9. Para ampliar ver http://1239manuel.blogspot.com/, recuperado el $27 / 03 / 2016$.
} 


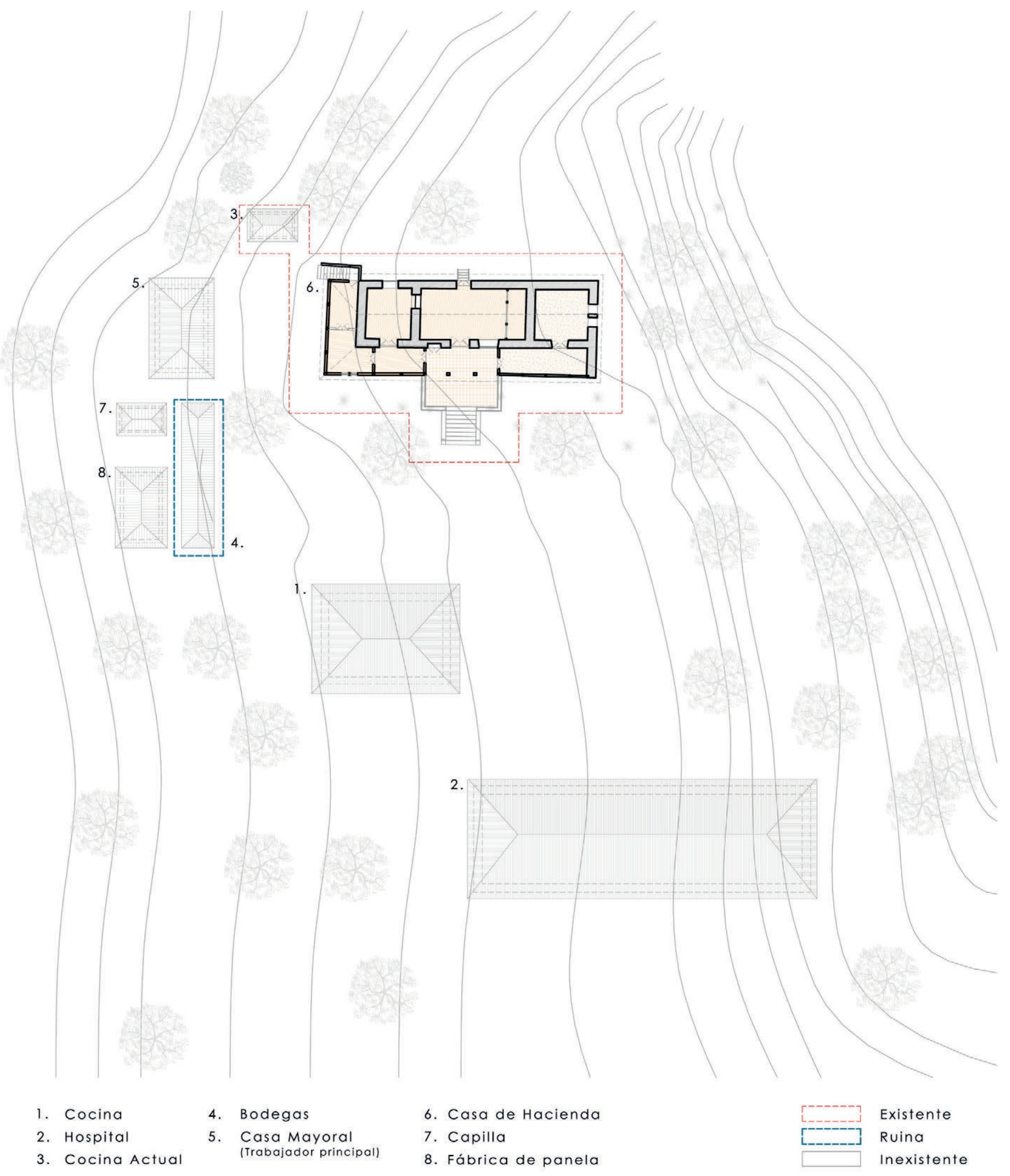

Casa de hacienda de Shuracpamba y el antiguo complejo hacendario Emplazamiento

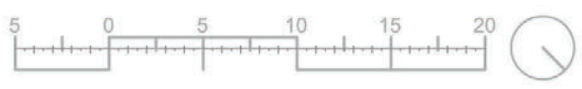

Figura 1. Casa de Hacienda de Shuracpamba y el antiguo complejo hacendario. (Elaboración: Aguirre 2016) 
que se conducían desde la zona hacia Perú, algunos de ellos para su exportación a Europa ${ }^{10}$. Define también el hilo de sesión de El Tablón, relacionado por las líneas Serrano y Valdivieso, con las Haciendas de Shuracpamba y Susudel.

Entre los descendientes en línea Valdivieso se encuentra Agustín Valdivieso Arteaga, a quien Rodolfo Pérez Pimentel, en su Diccionario Biográfico del Ecuador, lo identifica como propietario de la Hacienda de Shuracpamba en Oña ${ }^{11}$, padre de Alejandro y Agustín Valdivieso $\mathrm{Pozo}^{12}$ y sus 3 hermanas. Por este grupo familiar se sabe que la hacienda de 3 mil ha. ${ }^{13}$, fue gran productora de caña de azúcar y sus derivados — con énfasis en el aguardiente-, así como de mieses y la crianza de ganado vacuno, caballar y caprino. Espinoza (2012) indica que en la época, los más celebres corrales de ganado equino se encontraban localizados en la zona, así como en Yunguilla.

De Agustín Valdivieso Pozo, autor del libro Valdivieso: el valle, el apellido y la familia (1991), que recoge la cronología familiar como fruto de una intensa búsqueda en el sur del Ecuador, su amplio dominio documental y disfrute de material privilegiado ${ }^{14}$, se desprende fácilmente la cronología de propietarios, todos ascendientes suyos (Valdivieso 2016a). En 1581 y habiéndose concretado la merced de tierras, la Hacienda de Shuracpamba fue de Don Antonio de Mora y de la Serna, al contraer nupcias con Doña Agustina de Contreras y Cajas de Ayala ${ }^{15}$. Años más tarde el inmueble es de propiedad de Don Sebastián Serrano de Mora y Morillo de Montalván, que al contraer nupcias con Doña Teresa Coronel de Mora — quien hereda de su padre la propiedad, conjuntamente con las de Susudel, El Paso, Granadilla y Yunguillapamba-, la lega a su hijo Don José Serrano Coronel de Mora (Valdivieso 2016a).

10. La más importante de ellas en su momento sería la quinina o cascarilla. 11. Para ampliar ver http://www.diccionariobiograficoecuador.com/tomos/ tomo13/v2.htm, recuperado el 28/03/2016.

12. Identificado en el presente y en diversos textos como Taita Alejandro o Taita Alejo.

13. Se considera esta extensión entre los límites de las quebradas de El Rompe y la Tranca, la Cordillera de Allpachaca y el río León. Años más tarde se ampliará, siendo en comparación al tiempo de Valdivieso Jaramillo y Valdivieso Arteaga, notablemente inferior. (Valdivieso 2016b).

14. Hace referencia a un conjunto de elementos de carpintería: puertas, hojas de ventanas y objetos muebles de alto valor artístico que formaron parte de la casa de hacienda. El más importante, el dintel con la inscripción de fecha y autores del edificio (Valdivieso 2016a).

15. Se trata de una hija de Don Pedro Cajas de Ayala, uno de los fundadores de Cuenca, Santa Ana de los ríos de Cuenca, el 12 de abril de 1557. (Chacón 1977)
Los vestigios de la antigua fábrica de panela ${ }^{16} \mathrm{y}$ la casa de hacienda pueden tener su origen en esta época. Serrano Coronel de Mora lega tanto Susudel como Shuracpamba a su hijo Bartolomé Eugenio, quien la vende a Don Fernando Valdivieso de la Carrera, hermano de Sebastián, propietario de la Hacienda El Tablón. En adelante, Don Agustín Valdivieso Jaramillo quien la recibe parcialmente en herencia, permutará la propiedad, y a través de él, su hijo Don Agustín Valdivieso Arteaga la cederá en legado a sus descendientes. Alejandro Valdivieso Pozo, la conserva (Valdivieso 2016a).

De lo previo se deriva una transferencia directa del legado, influenciada por aspectos económicos, políticos, administrativos y sociales, propios de la historia del Ecuador ${ }^{17}$. En 1964 -momento en el cual el propietario es Don Agustín Valdivieso Arteaga - la Ley de Reforma Agraria y Colonización desmembró la propiedad, mediante un proceso de reparcelación para los huasipungueros ${ }^{18}$, para su posesión, uso y usufructo.

Desde el ámbito arquitectónico, el escaso o nulo estudio del complejo - tanto de lo existente como de lo desaparecido- desde la perspectiva arquitectónica motiva la realización de la presente investigación (Fig. 1). El grabado en el dintel del ingreso principal denota que el edificio se terminó de construir el 28 de noviembre de 1773, siendo Antonio López el maestro constructor y, Antonio Bega, el maestro carpintero (Fig. 2). Sobre ellos Valdivieso (2016b) afirma que fueron quienes también construyeron el complejo hacendario de Susudel, aunque de dicha relación no se tiene documentación fehaciente. Autores como Martínez (1983) y Arteaga (2008), hablan también de la presencia en la zona del artista Joan de Orellana para la ejecución de los trabajos

16. Históricamente en el sector se producía panela y aguardiente. Algo del equipamiento y enseres para estos procesos reposan en la casa de hacienda conservada. Sobre el edifico en sí se sabe que se consumió en un siniestro que lo inhabilitó permanentemente, quedando minúsculos vestigios. Sin ser el único suceso de esta naturaleza, años más tarde otro extinguiría la capilla, localizada en las proximidades de la casa hacienda (Valdivieso 2016a), del complejo arquitectónico que hoy se forma de 3 edificios (casa hacienda objeto de estudio del presente, cocina (edificación pequeña y actual) y antiguas bodegas en ruinas).

17. Ver Espinoza 2012. Patrimonio Histórico Urbano-Regional del Azuay (1800-2010), Historia del Azuay: estudios de caso. Memorias del II Encuentro Nacional de Historia de la Provincia del Azuay. Prefectura del Azuay y Universidad de Cuenca, Cuenca, Ecuador.

18. Se entiende por tal a cada área o cuerpo de terreno que localizados en un latifundio. Eran cedidos a los trabajadores de la hacienda para gozar de sus beneficios, a cambio de trabajo. Obras literarias fundamentales de la producción ecuatoriana como Huasipungo de Jorge Icaza (1934), narran la vida de los indígenas ecuatorianos en la época. 
en la Capilla de Susudel, pudiéndose presumir que el denominado retablo móvil o tríptico ${ }^{19}$ que permaneció en Shuracpamba hasta 1875 , fuese de su autoría, quedando

19. Del mencionado objeto no se ha identificado exista documentación previa al presente. Su propietario lo conserva conjuntamente con un ejemplar de igual factura, pero no vinculado a la Hacienda. Destacan en su tamaño (45 $\mathrm{cm}$ de alto por $22 \mathrm{~cm}$ de ancho) los detalles de pintura tabular que muestra a la Virgen del Rosario al centro, San Francisco y San Ignacio. Los Santos Sebastián, Miguel, Antonio y Agustín, en las hojas desplegables, cierran el objeto. Llama la atención la coincidencia con los propietarios del fundo en línea Valdivieso.

Se ha encontrado en el sitio otro objeto similar, que sin ser contemporánea, que guarda relación de características formales y dedicación al anterior. sin embargo clara la necesidad de estudios a detalle tanto de técnicas, como de materiales, para descartar esta hipótesis o su posible vinculo con la Escuela Quiteña (Valdivieso 2016a) (Fig. 3).

A nivel formal el edificio se muestra sobrio. Sus anchos muros de adobe evidencian gran dominio de la técnica constructiva del aparejo soga-tizón, con base en el empleo del material local ${ }^{20}$, sin recurrir, empero, a los

20. Para evidencia de tal, Susudel y sus alrededores, hasta la actualidad son conocidos por la fabricación a gran escala de ladrillo artesanal. Moscoso (s/f, 4) ratifica está situación.

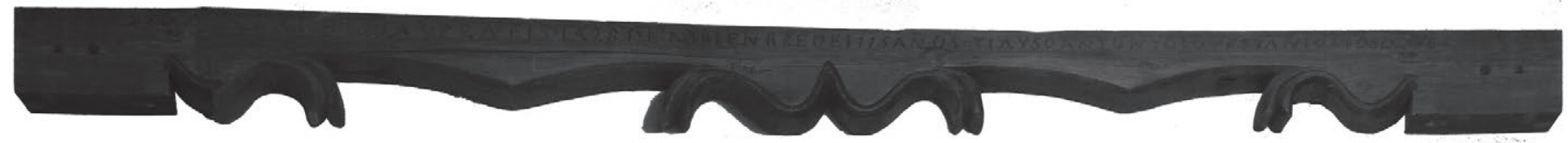

Figura 2. Dintel con inscripción. (Fotografía: Aguirre 2016)

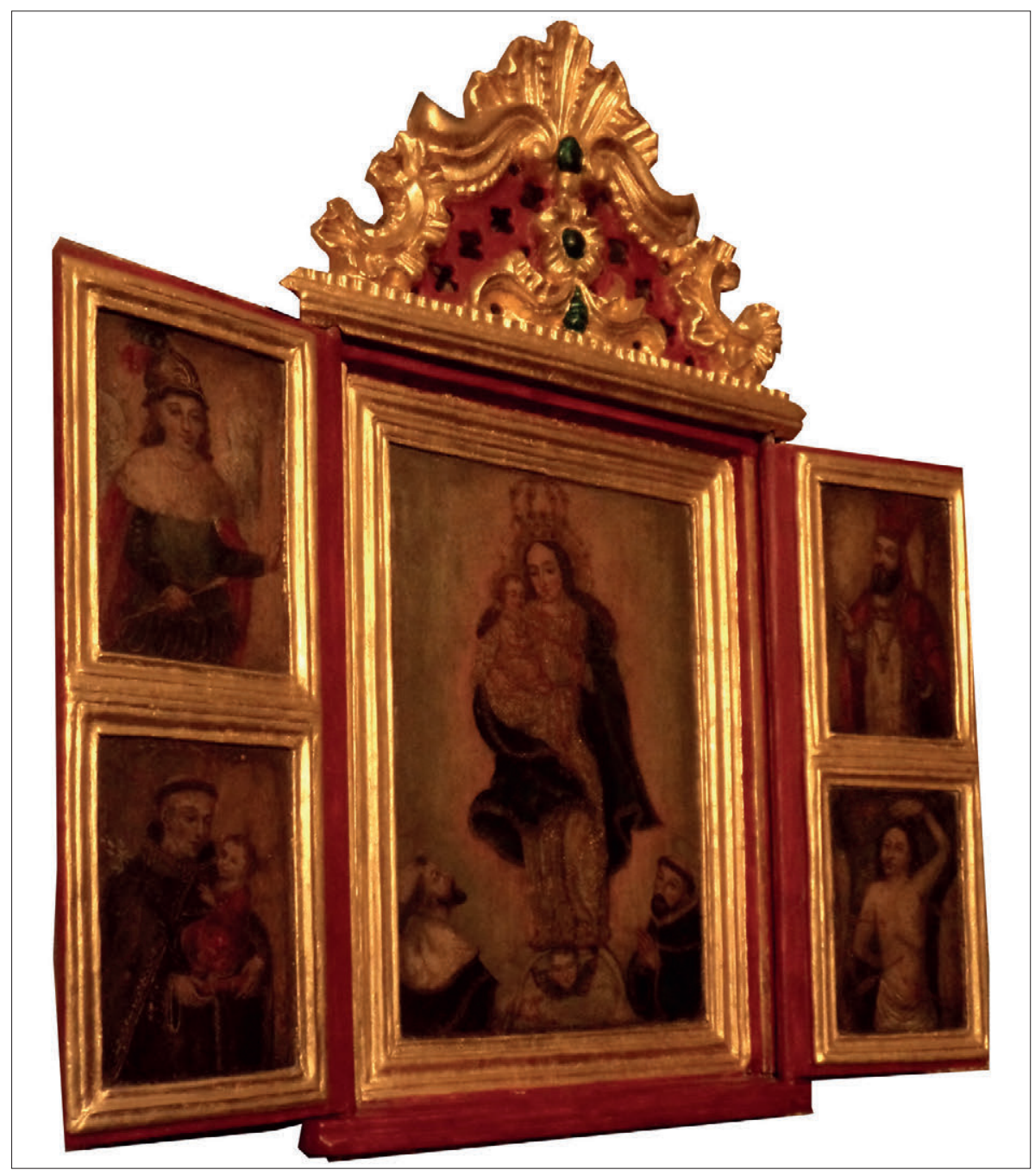

Figura 3. Retablo móvil o tríptico.

(Fotografía: Aguirre 2016) 
pigmentos naturales (tierra de color) como acabado ${ }^{21}$. $\mathrm{Su}$ volumen se desarrolla en un solo nivel adaptado a la topografía del sitio, predominantemente rugosa (Fig. 4), lo cual garantiza su posicionamiento estratégico en términos administrativos históricos ${ }^{22}$. Se compone de tres ambientes claramente reconocibles, rodeados en dos de sus lados por el que fuese un antiguo portal, desde cuyo extremo la visión domina el territorio. Hacia el centro, se ubica la escalera de acceso que marca el eje de simetría parcial del edificio y nos enfrenta a la puerta principal con sitio del dintel de la inscripción. El edificio se corona con cubierta de estructura de madera de guagual o Myricaceae, enchacleado $^{23}$ de carrizo $^{24}$ - Arundo donax - y paja, $\mathrm{y}$ tejas sobre mortero de tierra. Las características formales y constructivas del remate sobresalen por la notable influencia mudéjar visible en el tirante central con decoraciones geométricas, apoyado en canes o ménsulas de buena factura y decoración, así como en la forma y disposición de tirantes, zapatas o monterillas (Fig. 5). Es posible que se trate de uno de los pocos ejemplares de esta factura en la región y que de manera general exponga la realidad arquitectónica y artística del complejo (Fig. 1), hoy muy venido a menos.

Con reflexión y análisis propios de la Antropología, Bravo Díaz (2013) aborda los componentes materiales e inmateriales relacionados a la Hacienda de Shuracpamba. La práctica de la Medicina Ancestral refiere de manera inmediata a las figuras del Taita ${ }^{25}$ Alejandro Valdivieso y su hijo Juan Alejandro, por las leyendas mágicas que se cuentan del sitio (Bravo 2013: 76), incluso desde su influencia como formadores en la práctica del chamanismo ${ }^{26}$. De esta práctica, con certeza se sabe que desde época de Doña Ignacia Riofrío

21. Esta práctica es muy común en la zona, incluso a día de hoy y por la abundancia del material en cantidad y tonos se sigue utilizando. Al respecto Moscoso $(\mathrm{s} / \mathrm{f}, 10)$ indica que dichas pinturas - y sobre el caso de Susudel y Oña, asentamientos cercanos-, siguen dándole a su arquitectura ese carácter auténtico y pintoresco que se han ido perdiendo poco a poco otros sectores del país. 22. Su ubicación permite control y dominio del territorio, y por tanto su directa distribución en relación a mano de obra y productividad, vínculos de familia, etc., incluso luego de 1964.

23. Usado para referirse a la estructura de bambúes, colocados sobre la estructura de la cubierta de un edificio y atados entre sí con una fibra vegetal, generalmente cabuya, proveniente de los pencos o agaves.

24. Al igual que el suro (Chusque scandens), se trata de una gramínea típica del Austro y una de las 5 especies andinas identificadas en el Ecuador (Altamirano 2011).

25. Traducción de padre, al quechua.

26. Ver Carrasco 2002. Shuracpamba, el peyote y el Fuego del Itzachilatán. Cáñamo: La revista de la cultura del cannabis, 53: 102-106.

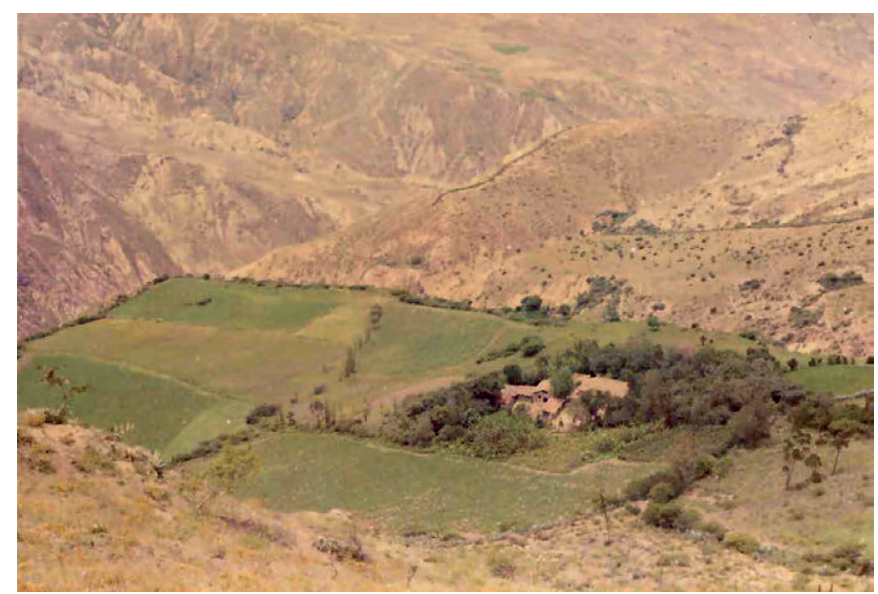

Figura 4. Vista área del conjunto hacendario hacia 1950 aproximadamente. (Fotografía: Archivo Histórico-Fotográfico de Agustín Valdivieso Pozo, Cuenca.)

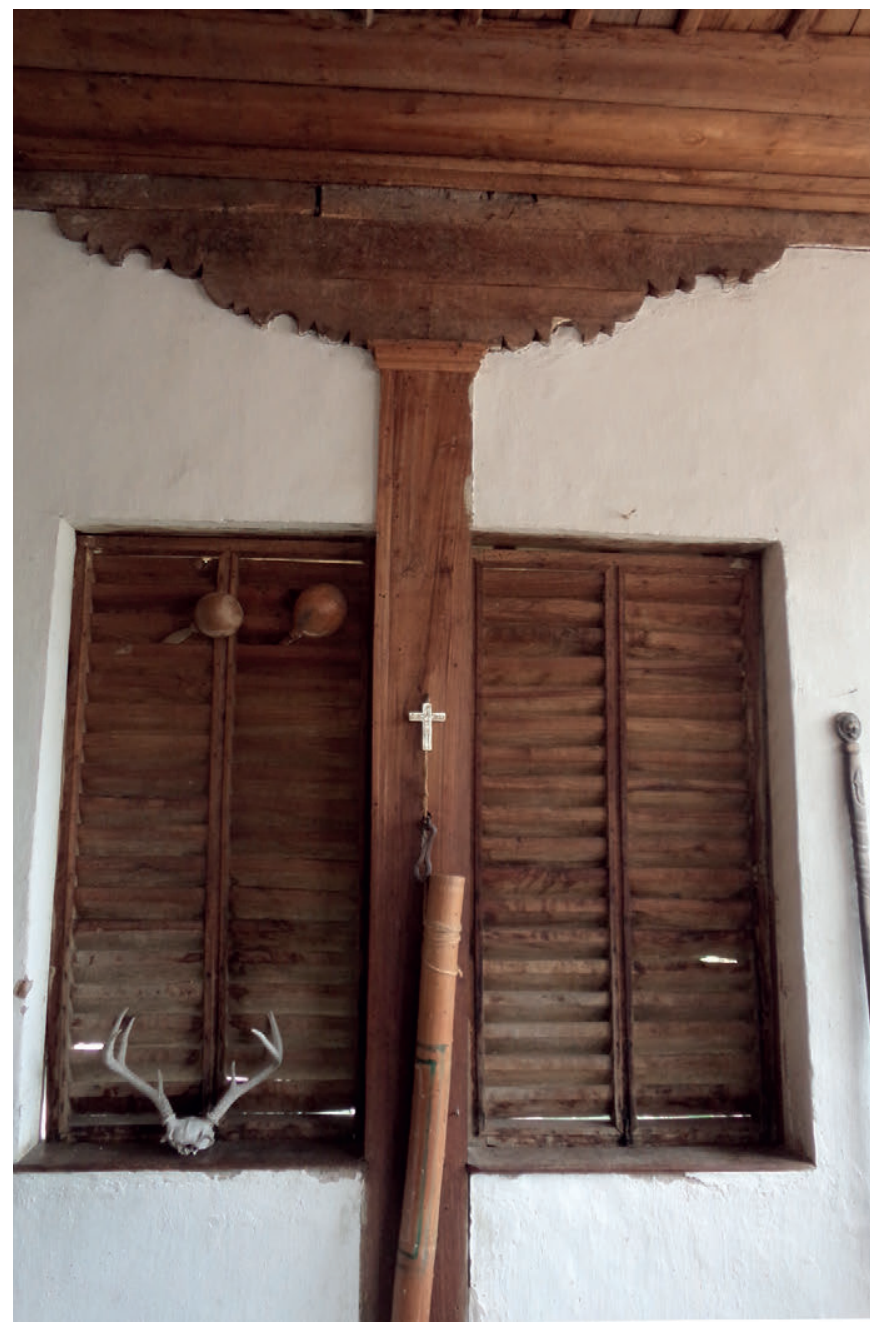

Figura 5. Detalle de monterilla. (Fotografía: Aguirre 2016)

Celi, esposa de Don José Serrano y Jaramillo, se desarrolló para dar tratamiento a diversas dolencias, con especial 
énfasis en el mal gálico ${ }^{27}$. Ante dicha labor, la hacienda sufrió una ampliación ${ }^{28}$ (Fig. 1).

Sobre este vasto antecedente histórico que evidencia tantos nuevos intereses de investigación, como la necesidad de profundizar en otros (sociales, culturales, económicos, administrativos, etc.), incluso inexistentes o no intencionados (Riegl 1905), se inició la investigación arquitectónica y patrimonial, desde la empresa estratigráfica enfocada en un componente del antiguo complejo arquitectónico (Fig. 1), es decir, desde un segmento de la obra de arte y no desde su integridad (Brandi 1988). El punto de partida teórico universal, Edward Harris, y el libro Principios de estratigrafía arqueológica, así como la adaptación de Parenti, Francovich y Brogiolo respecto del conocimiento de los procesos y técnicas constructivas, así como al contexto cultural (Doglioni 1997). Aunque el repertorio teórico es vasto, e incluye a exponentes como los anteriores, además de otros y sus múltiples aportaciones, como Luis Caballero Zoreda, Agustín Azkárate, Martín Talaverano, Camilla Mileto y Fernando Vegas (2010), Antonio Almagro, etc., se ha considerado como referente directo al trabajo de Rolón y Rotondaro (2010) sobre el estudio de la vivienda rural vernácula construida con tierra en la Rioja, que eleva el nivel de conocimiento a la vez de ratificar la aplicabilidad del método. En asistencia de otros se extrapola al territorio a través de clusters o grupos constructivos homogéneos y su variabilidad en el estudio de edificios históricos (Rolón 2014), enunciado por Parenti (1995).

\section{MÉTODO}

El acercamiento documental al caso de estudio, así el aporte de las fuentes orales, si bien han expuesto datos e información extraordinaria, no trasciende hasta la médula de la evolución del bien, sus diversas etapas y las del complejo. Esta particularidad es propia del análisis estratigráfico constructivo (Tabales 2002).

En la práctica del análisis estratigráfico que envuelve a la Hacienda de Shuracpamba, se ha aplicado la propuesta metodológica de Caballero Zoreda (1995)

27. Se denomina así a la sífilis. La hipótesis más aceptada proviene de documentación de autores españoles como Ramón Pané, Fray Bartotomé de las Casas, Gonzalo Fernández de Oviedo y Rodrigo Díaz de Isla, sugiriendo que se trata de una enfermedad endémica de América Central que por los viajes de Colón y la propia conquista se extendió por el Viejo y Nuevo Mundo. Para ver más consultar Linares, Sáenz, Pérez, Clemente y Maganto 2013.

28. Se trataría de un cuerpo rectangular. El primero hacia el Norte y próximo al acceso, posiblemente el hospital. (Valdivieso: 2016.a). y previamente ensayada en la Iglesia de Santo Domingo de Guzmán en Pajarejos, Segovia ${ }^{29}$, cuyo procedimiento se compone de siete pasos. El primero de levantamiento fotográfico y fotogramétrico - en este caso parcial por las densa vegetación que ronda al edificio en varios sectores - y desarrollo de planimetrías base $^{30}$, en donde a partir de croquis in situ, posteriormente apoyados en software especializado, permiten desarrollar el ejercicio de análisis e identificación de elementos. A continuación se procede a la identificación, numeración y descripción de las Unidades Estratigráficas Murarias - UEM - in situ, también, y con ello la primera aproximación material y constructiva (Caballero 1995: 39). La observación, identificación y rotulación ${ }^{31}$, de la totalidad de UEM (Sánchez 2004) se realiza bajo un mecanismo propio de codificación ${ }^{32}$. En adelante se conforman ortofotos - parciales y específicas - utilizando el software Agisoft Photoscan y Adobe Photoshop, mientras Autocad Autodesk, para el tratamiento de dibujos técnicos. Ambos insumos asisten en la delimitación de las UEM y verificación de notas de campo, apoyado en fichas analíticas y de caracterización de cada $\mathrm{UEM}^{33}$.

Como tercer momento, se encuentra la lectura de relaciones temporales y construcción de diagramas según los principios de homogeneidad, individualidad $\mathrm{y}$ temporalidad, para relacionar, vincular y ordenar elementos por espacio y posteriormente, tiempo, lo cual conduce directamente al cuarto momento, la construcción del diagrama estratigráfico Harris Matrix, que a efectos del caso de estudio, no ha representado una verdadera simplificación de los procesos anteriores, sino un ejercicio de ordenamiento de las UEM, con base en parámetros de correlación y periodización. El proceso atiende así a etapas constructivas, frente a la periodización clásica (Harris 1991: 159), obteniendo una cronología relativa. (Aguirre y Álvarez 2015).

En adelante las etapas restantes, son menos intensas. A partir del diagrama estratigráfico, se procede a la

\footnotetext{
29 Para ampliar información consultar Aguirre y Álvarez 2015.

30 Se emplearon herramientas técnicas como cinta métrica, distansiómetro láser, flexómetro rígido y jalón.

31 Aunque Azkárate (2010: 59) recomienda la georreferenciación de las UEM, considerando la monumentalidad del caso de estudio no se aplica. 32 Dicho mecanismo no se vincula al orden de identificación de las UEM y se ajusta a sus propias condiciones. En opinión de Luis Caballero Zoreda, anticipado por Parenti (1988), sería potencialmente aleatorio. Para el caso de estudio está dada por: Punto Cardinal Principal de Orientación_Número. 33 Esta herramienta y proceso derivado permiten comparar, relacionar y precisar aquellos aspectos de carácter problemático iniciales. (Aguirre y Álvarez 2015).
} 
vinculación con la documentación histórica para el establecimiento — cuando lo es posible - de la cronología absoluta de las campañas constructivas ${ }^{34}$. Finalmente se da paso a las conclusiones, construidas sobre la base de los pasos previos y la definición de la hipótesis históricoconstructiva. El punto culmen está en la aportación de dibujos planimétricos de las UEM y la construcción definitiva del diagrama estratigráfico.

Como consideración última, se encuentra la etapa de archivo de datos/publicación, con lo cual la difusión de resultados cumple efectivamente la labor paliativa del desconocimiento generalizado. Para tal efecto, se pretende difundir el presente en el ámbito local vinculada principalmente desde la vertiente histórica, así como a la comunidad académica y científica, como una contribución al estudio de la arquitectura hacendaria del sur del Ecuador en tiempos de colonia y república.

\section{RESULTADOS}

Al ensayar el método de análisis estratigráfico constructivo, se ha documentado el edificio principal del conjunto arquitectónico de la Hacienda de Shuracpamba, quedando pendientes los restantes -incluidos aquellos en estado de ruina-, y los desaparecidos (Fig. 1 y Fig. 4). Podría considerarse al edificio una obra autónoma, aunque ello signifique su evidente disminución, al quedar vinculado con el resto del complejo, no sólo desde la huella formal (Brandi 1988), sino desde la constructiva, temporal y social, es factible su comprensión.

Del proceso técnico-científico de investigación se obtuvieron 45 fichas de caracterización de las UEM - revisadas, omitidas redundancias y duplicados-, distribuidas en 19, 23, 2 y 1, en los paramentos Norte, Sur, Este y Oeste, respectivamente. Así mismo diversidad de material preliminar, que en conjunto han posibilitado la determinación de las cinco fases constructivas, de ellas al menos dos de cambio o incorporación de materiales y técnicas constructivas (Fig. 6). Investigar aquello exige más que la secuenciación insertada en el diagrama estratigráfico, más cuando las fuentes documentales explícitas son limitadas. Su diversidad denuncia la existencia de

34. Al respecto se han consultado los fondos documentales del Archivo Nacional de Historia, sección del Azuay, entre el 11 de diciembre de 2015 y el 25 de marzo de 2016. Así como diversa documentación secundaria, que recoge aunque de manera parcial y atendiendo a interés particulares alguna información. cambios socio económicos (Azkárate, Barreiro, Criado, García, Gutiérrez, Quirós y Salvatierra 2009: 601), a su vez ratificados siguiendo a detalle una comparativa entre la historia de la nación y la herencia de sucesión de la propiedad. Incluso por legado, desde la sabiduría popular debe ser considerado su conocimiento a detalle en futuras investigaciones, extensible al ámbito territorial y cronotipológico.

Dejando de un lado el ámbito arquitectónico e investigativo del edificio, — que se retomará en breve- y los vestigios de lo que fuese el complejo arquitectónico, y con referencia en Icaza (1934) se evidencia que pudo más la incidencia política y administrativa sobre la redistribución de los históricos latifundios que el verdadero énfasis de progreso y desarrollo económico, social y territorial. Derivadas de dicha ley y sus efectos colaterales, persisten a día de hoy situaciones como las denominadas "migraciones golondrinas" o estacionales se transformaron en permanentes, tanto en lo nacional como internacional ${ }^{35}$, y con ellas el abandono del territorio, despoblamiento incluyendo las transformaciones que a nivel familiar se generan - y olvido de la práctica de actividades y saberes vinculados a los rasgos de identidad. Situaciones todas que afectaron a Shuracpamba y sus contemporáneas, que aún no se superan.

Retomando la lectura estratigráfica, a partir del diagrama (Fig. 7), los alzados (Fig. 8a y 8b) y las planimetrías de evolución (Fig. 6), se determinan las etapas constructivas, quedando de la siguiente manera. La primera, iniciada en 1773 se extiende aproximadamente tres décadas e incluye la implantación de la edificación, seguramente de manera conjunta con los edificios desaparecidos y en ruina (Fig. 1). A nivel arquitectónico el tipo se evidencia como una sola crujía rodada perimetralmente por el portal — hoy cerrado y cambiado de usos- - Los materiales empleados son tierra - de las cercanías, del sitio de Pullcanga - a manera de cielo raso y mampostería de adobe, alcanzando entre 70 y $86 \mathrm{~cm}$ de sección, madera para carpinterías y cubierta, piedra local con especial coloración rojiza en basas de columnas y escaleras, hoy desaparecidas (Valdivieso 2016a) (Fig. 9). Son propios de este momento el conjunto de carpinterías de nogal talladas con motivos geométricos y el conjunto

35. A nivel nacional las primeras surgieron en el siglo XIX principalmente por el auge cacaotero y luego bananero, haciendo que los habitantes de la sierra se trasladen a la costa durante temporadas específicas. En el ámbito internacional hasta los años sesenta eran frecuentes sobre todo desde el ámbito económico y social. En adelante la situación empeora como consecuencia del deterioro de las condiciones de vida y acceso al trabajo en el Ecuador. 


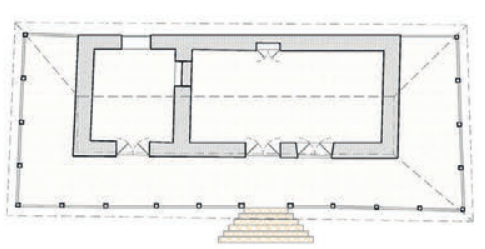

01 fase

1773. Construcción.

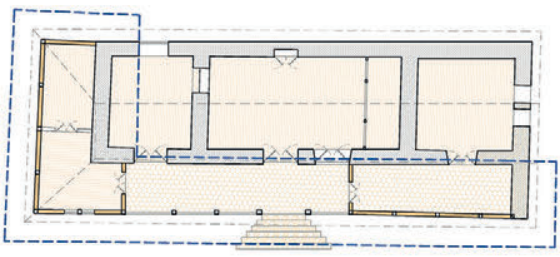

03 fase

inicios XIX. primeras modificaciones en portales y pavimentos

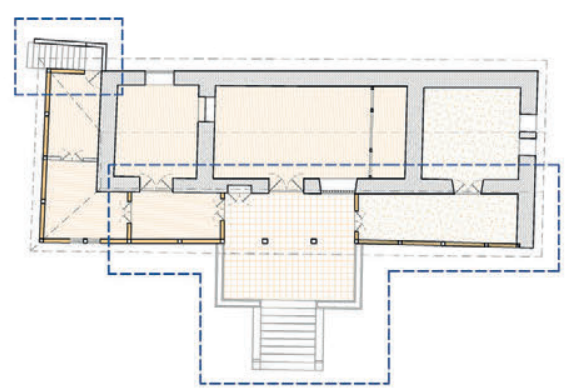

04 fase

segunda mitad XIX. Intervenciones modernas.

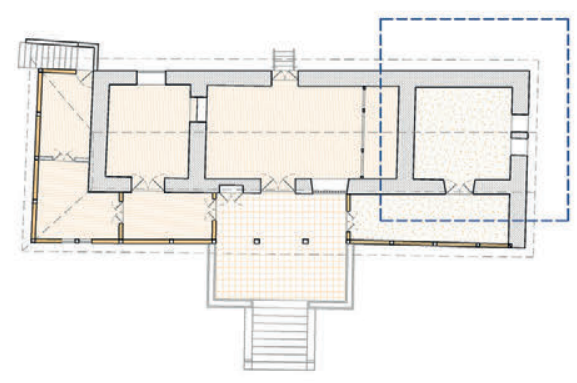

05 fase

$X X I$. Reparaciones emergentes.

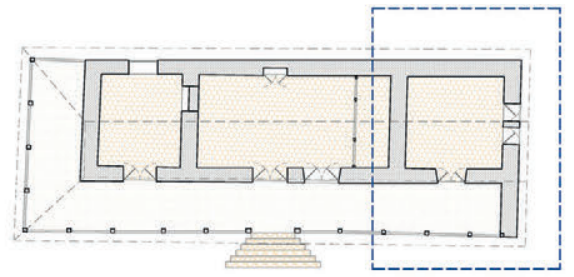

02 fase

1800?. Ampliación general.

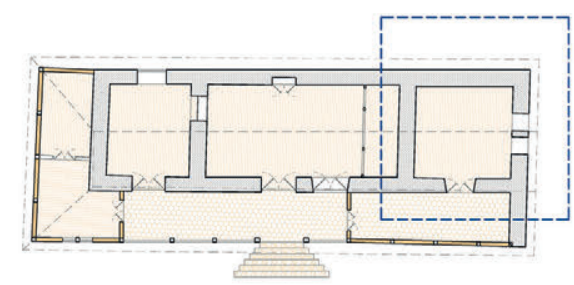

03.1 fase

mediados XIX. reconstrucción de la ampliación.

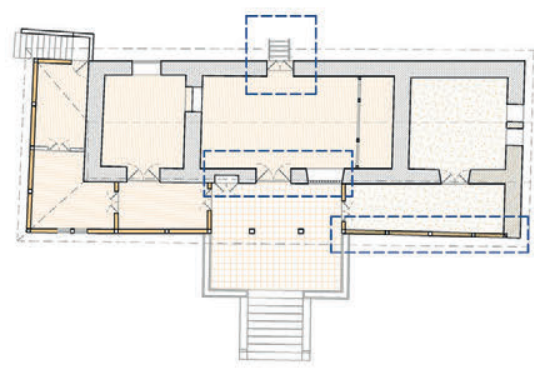

04.1 fase

finales $X X$. extracción de elementos.
Figura 6. Evolución planimétrica del edificio entre 1773 y la actualidad. (Elaboración: Aguirre 2016) 
de monterillas de madera que coronan las columnas para dar paso a la cubierta (Fig. 5). Sobre la última, sus características intrínsecas y poco frecuentes en el territorio, demandan un análisis minucioso, en tanto a forma y razón de su implementación en el lugar (Fig. 10), con lo cual se suma a la lista de intereses investigativos futuros.

Con la ampliación del aposento hacia el Oeste y la evidente reforma de la cubierta, se define la segunda etapa constructiva, siendo la muestra más fehaciente la acentuada grieta del muro Sur (Fig. 11), que se observa desde el exterior no empañetado ni revocado. A nivel funcional, pero en el mismo espacio arquitectónico, se aprecia la existencia de otra(s) dependencias entre el antiguo muro de cierre del edificio hacia el Oeste, y la estructura auxiliar dispuesta para dar soporte a la cubierta. Puede suponerse que fuesen dormitorios de servicio para los sirvientes de mayor confianza, que en lo posterior se convirtieron en trojes - espacios propios para el almacenamiento de cereales - o depósitos de granos (Valdivieso 2016a).

Con la habilitación parcial del portal, hacia el Noreste y bordeando el aposento principal, se define la tercera etapa. En ella se incluye la incorporación de madera para pavimentos, rastreras y zócalos, uno de los motivos obedece al cambio de su condición, hacia dormitorios, situación que se mantienen hasta la fecha, así como a una mejora importante en los réditos obtenidos, situación que posibilitó la inversión tanto en material de calidad, cuanto en mano de obra especializada que lo ejecute con propiedad. De manera importante esta intervención incide en la calidad estética del edificio, así como en el confort térmico y acústico ${ }^{36}$. Derivada de esta etapa, se encuentra la acción reconstructora del área de ampliación (segundo aposento hacia Oeste) (Valdivieso 2016b), que es la que persiste hasta la actualidad sin rastro de su antecesora.

En adelante, la cuarta etapa involucra un conjunto de intervenciones diversas. Una reparación en el área de la ampliación (segundo aposento hacia Oeste), así como la inserción de elementos inexistentes hasta ese momento, como la terraza frontal revestida de baldosa bicolor (blanca y roja), que desde la escalera da acceso a la vivienda. Su ubicación si bien corresponde a la escalera original de la fase 1 , en tamaño y materialidad es

36 Las mediciones, aunque puntuales, se realizaron con los siguientes equipos Termohigrómetro - anemómetro Kestrel 4000, para medición de condiciones ambientales en general, Luxómetro Sper Cientific 84006, Sonómetro OHLSS-1 y Pirómetro OS425-LS. Los resultados reflejaron condiciones de temperatura y humedad relativa, prácticamente constantes en los ambientes donde se realizó esta intervención, así como máximas condiciones de confort auditivo y de iluminación.

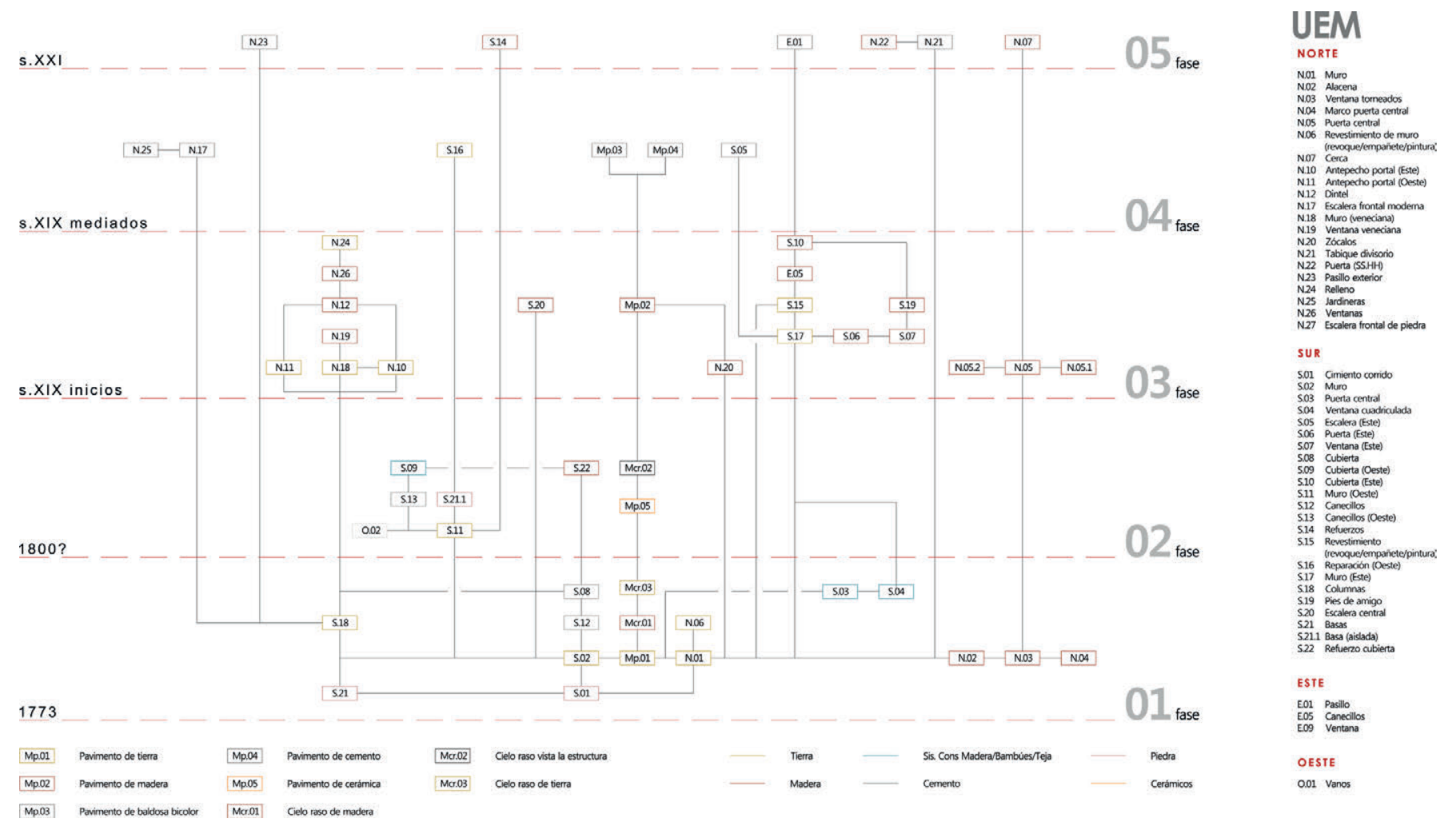

Figura 7. Diagrama estratigráfico (Harris Matrix). (Elaboración: Aguirre 2016) 

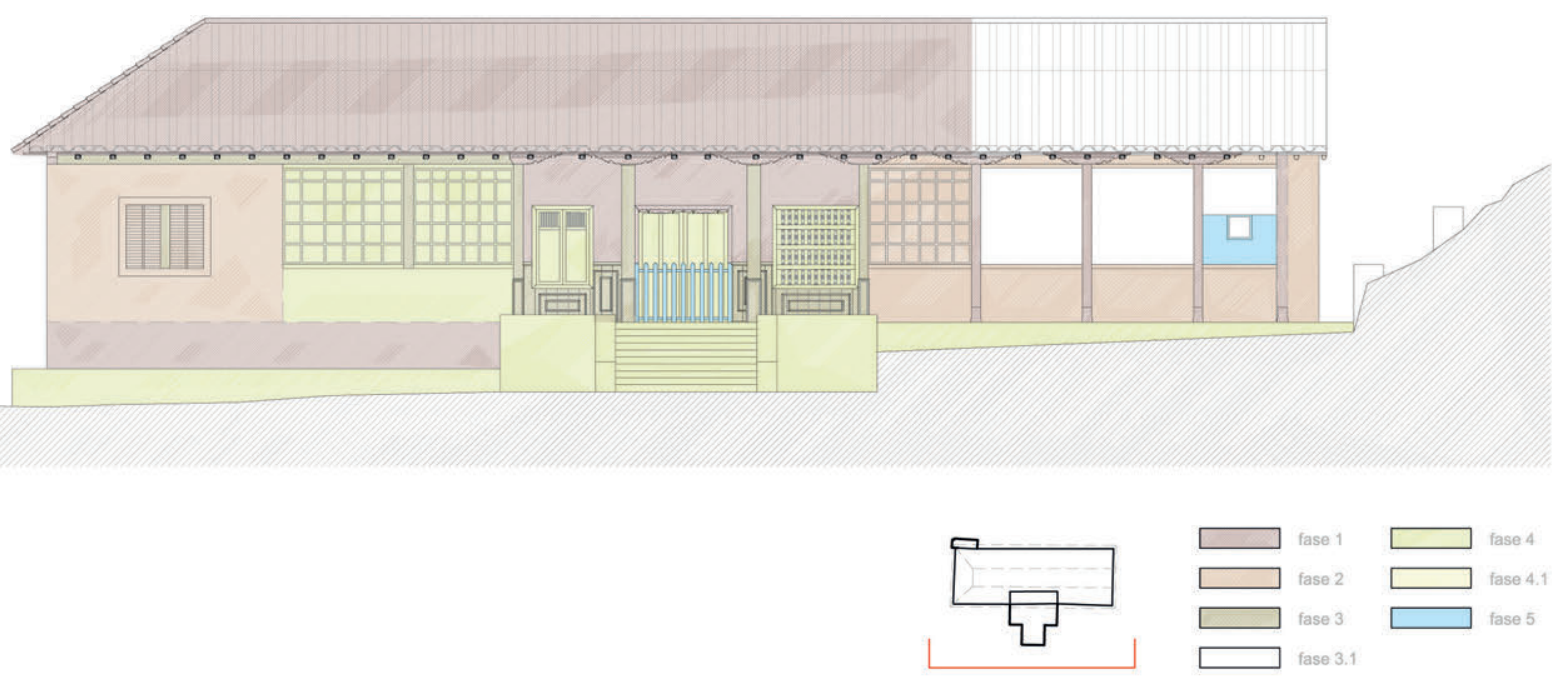

\section{Casa de hacienda de Shuracpamba Alzado estratigráfico Norte}

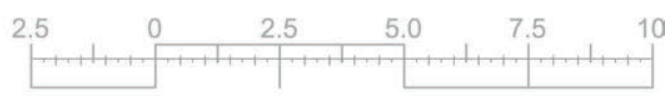

Figura 8.a. Alzado estratigráfico Norte. (Elaboración: Aguirre 2016)

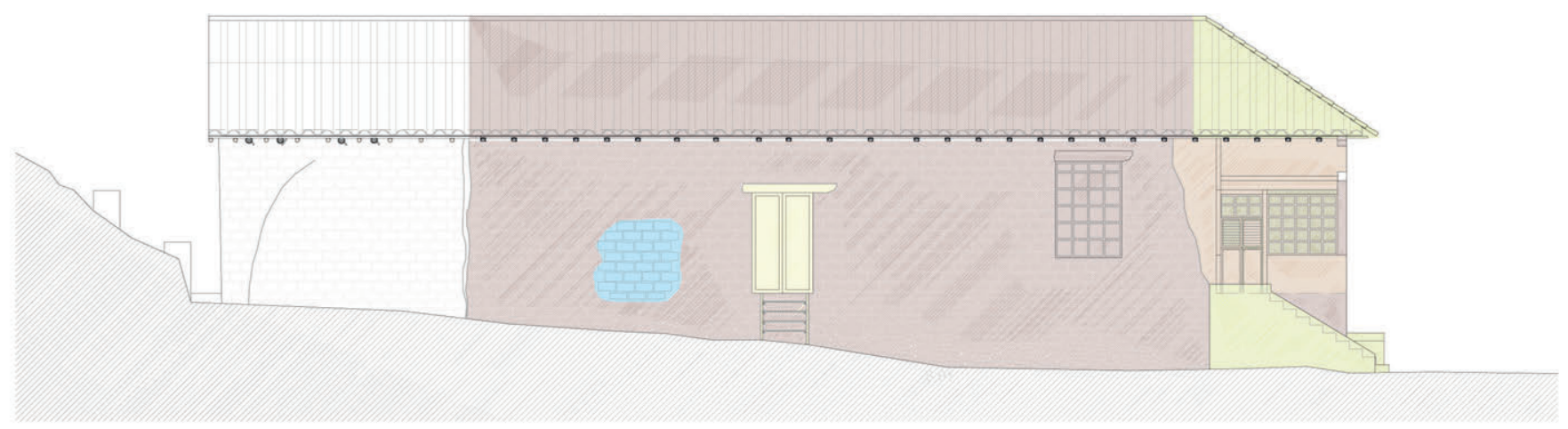

\section{Casa de hacienda de Shuracpamba Alzado estratigráfico Sur}

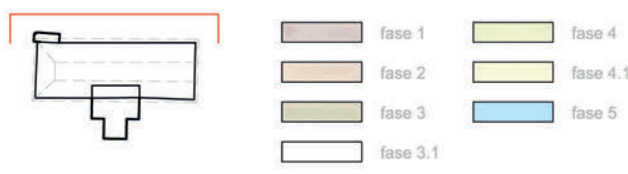

Figura 8b. Alzado estratigráfico Sur. (Elaboración: Aguirre 2016)

totalmente contraria, evidenciando con ello las nuevas necesidades de los ocupantes, sino también sus afinidades estéticas que desplazan a las prácticas, materiales y técnicas usadas hasta el momento. De esto también se deriva la incorporación de la escalera introducida en el paramento sur (Fig. 8b), desde el antiguo portal (luego dormitorio) y con conexión hacia el exterior. Posteriormente otras intervenciones provocarán el reemplazo de las carpinterías de puertas y ventanas —originales - de madera tallada de nogal y modelos geométricos, por las actuales de madera de eucalipto ${ }^{37}$ — especie introducida en el Ecuador a mediados del siglo XIX y ampliamente

37. Aunque es una especie exótica, su presencia y amplio despliegue, contribuye a la definición paisajística de numerosos asentamientos de la sierra ecuatoriana, implantado en un intento de modernización con sentido ecologista para recuperar los bosques nativos desaparecidos. El contexto territorial de Shuracpamba se ve inmerso, pero El caso de Shuracpamba es otro, no así su contexto territorial inmediato. Su aspecto cambió derivado del abandono. 

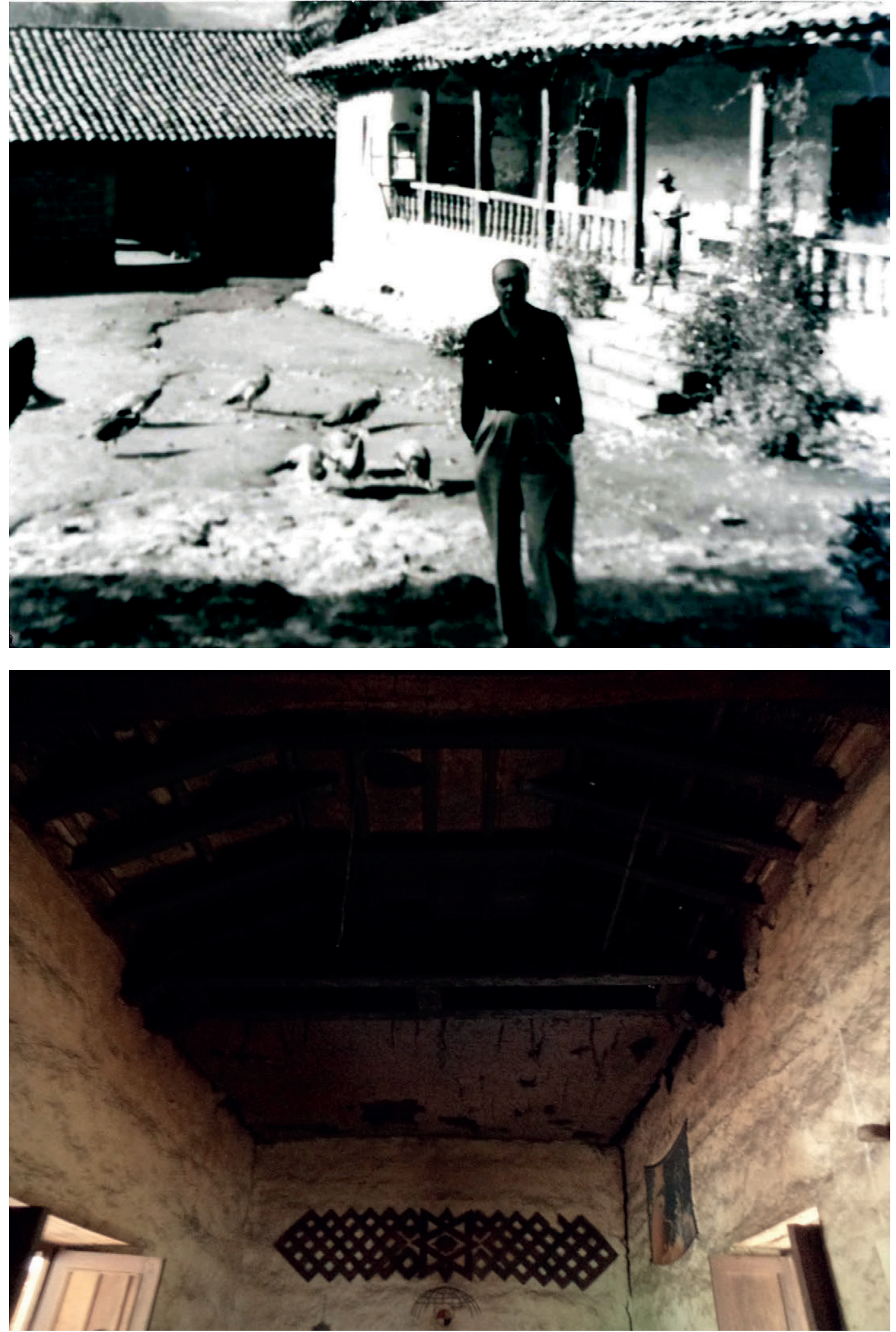

Figura 9. Imagen de Don Agustín Valdivieso Arteaga, de fondo la casa de hacienda. (Fotografía: Archivo Histórico-

Fotográfico de Agustín Valdivieso Pozo, Cuenca.)
Figura 10. Vista interior de la estructura de cubierta. (Fotografía: Aguirre 2016) utilizada en carpintería - y de menor calidad artística, a excepción de la denominada UEM N.03 (Fig. 8a). En este mismo contexto, el dintel de la inscripción de datación del edificio será una de las piezas que formando este conjunto de extracciones se desplazarán hasta Cuenca, como objetos suntuarios, dejando evidencia 


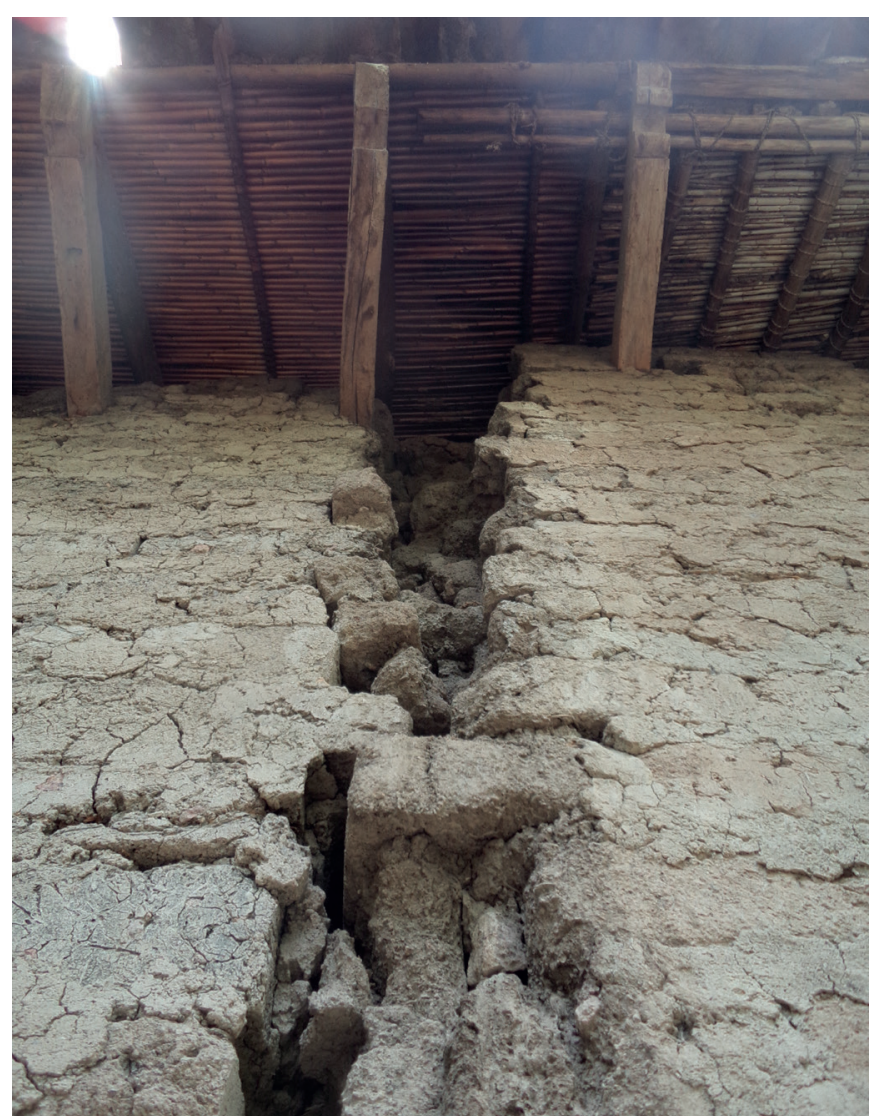

Figura 11. Grieta en el muro Sur. (Fotografía: Aguirre 2016)

en jambas y dinteles del mecanismo de pivotaje que las operaba, y por tanto de su prematura ausencia motivada por un declive económico importante.

La alacena de la dependencia principal (N.02, Figura 8a) se desplazará hacia el paramento Norte y en su sitio se localizará la puerta actual y escaleras (con descripciones semejantes a las anteriormente acotadas). Caso semejante el de la veneciana simétricamente dispuesta en relación a la existente, hacia el Noroeste, y otros elementos de interés.

En la última etapa, menos venturosa que el resto, por intentar definir el vertiginoso proceso histórico del edificio y el complejo al que pertenece, se agrupan las intervenciones contemporáneas, de mínimas reparaciones, frente a los problemas identificados a simple vista. Entre ellas se encuentra la atadura o refuerzo de los muros Norte y Sur en el cuerpo aposento ampliado y luego reconstruido hacia el Oeste. Para este fin se han utilizado rústicas llaves de madera a nivel del coronamiento de ambos muros, perfectamente visibles. Otras actuaciones menores a nivel de superficie complementan la fase con la incorporación de un aseo delimitado por modernos paramentos de ladrillo y cemento.
Pese al paso del tiempo y la existencia de graves lesiones, cuya evidencia de mayor alerta se localizan en los muros Sur y Oeste, que experimentan un desplome de entre 15 y $30 \mathrm{~cm}$, el edificio es una muestra de calidad, solvencia y nobleza constructiva.

Sobre él el paso del tiempo no ha incidido tanto como la falta de mantenimiento e intervenciones oportunas (S.01, Figura 8a), que presentaría a día de hoy su situación como diferente. Bien pudiera entenderse este estadio como temporal, sin embargo, y reclamar por él aquello que Riegl (1905) define como valor limitado de la copia. Con lo cual la actual visión íntegra del edificio, su situación histórica y relevancia territorial, abordada desde la cadena de valor ${ }^{38}$ (Azkárate, Barreiro, Criado, García, Gutiérrez, Quirós y Salvatierra 2009: 609) la canalización de los resultados hacia el establecimiento de posibilidades concretas de actuación desde la práctica multidisciplinar, extendida además hacia sus realidades patrimoniales diversas y de las cuales se han intentado identificar hitos o elementos de relevancia.

\section{CONCLUSIONES}

En el caso de la casa hacienda de Shuracpamba y su potencial no limitado al ámbito arquitectónico, se fortalece como objeto de estudio transdisciplinar, donde la dimensión histórica es determinante.

Con la identificación de las cinco etapas constructivas del edificio principal conservado de Shuracpamba (Fig. 6), se expone una visión de la dinámica del lugar que incluye matices desde el ámbito social, económico y administrativo, así como las dimensiones patrimoniales material —arquitectónico, inmueble, territorial — e inmaterial vinculadas e indisolubles a ella hasta la actualidad. Todos considerados como testimonios diacrónicos de valor. Las transformaciones identificadas conciernen en buena medida con el proceso histórico comprendido entre 1773 y mediados del siglo XIX, correspondiéndose con las etapas de auge productivo de la hacienda, pero también a la imperiosa necesidad de hábitat y trabajo en potencial incremento que posibilite esta bonanza, frente a la pérdida de la fábrica de panela o mejor conocida en la cotidianeidad como "hacienda vieja". Estas acciones y las subsiguientes hasta la actualidad han posibilitado visibilizar lo definido por Choay (2007) sobre los planteamientos de Riegl y

38. Ver Azkárate, Barreiro, Criado, García, Gutiérrez, Quirós y Salvatierra 2009 . 
Giovannoni, como integración a la vida contemporánea, en su propio momento y contexto, que liberando al edificio (hablando por la casa de hacienda, no así del resto) de los riesgos de estar en desuso lo expone al desgaste y a las usurpaciones de uso, pero permiten su conservación material en el tiempo a través de la cual son factibles de identificar todas aquellas situaciones.

Sustentando lo anterior, con la nueva edificación implantada, y más representativa, si bien se mejoraron las condiciones de comunicación y relación con el territorio próximo fuera de los límites hacendarios, incluso a día de hoy, su posición geográfica sigue siendo un tema de análisis contrapuesto. Ha garantizado la conservación de elementos aislados del arquitectónico hacendario, a costo de su deterioro y las precarias condiciones de ocupación.

Al respecto del complejo arquitectónico integral, por la existencia de vestigios materiales in situ y la supervivencia de testimonios auténticos localizables (Brandi 1988), sería de interés su estudio en profundidad, con fines de gestión oportuna. Un importante ejercicio de reconstitución supondría un primer paso hacia el conocimiento del complejo así como de la realización de estudios tipológicos territoriales, incluso con fines didácticos. Deberá además considerarse el ambiente paisajístico monumental propio de la espacialidad arquitectónica (Brandi 1988; Latorre y Caballero 1995: 5-18), las manifestaciones sociales, culturales y de la técnica constructiva que el presente ha expuesto, como otras que contribuyan a su comprensión y preservación.

En tanto al ensayo del método de estudio, si bien es incipiente, se cree que su desarrollo debe continuarse con el fin de estudiar los rasgos tipológicos locales - en arquitectura menor y complejos hacendarios-, tanto desde la morfología y funciones como desde los sistemas constructivos y el empleo de materiales, para rebasar la mera noción de definición estilística unitaria. Ya desde las propias bondades del método se puede vislumbrar la factibilidad de su aplicación como medio de conocimiento integral arquitectónico de ejemplos menores, poco conocidos, etc., ya que su viabilidad a nivel teórico no está limitada y la inversión económica es mínima, aunque bien pudiese implicar la utilización de tecnología de última generación; para documentación, análisis de procesos patológicos, estudios de confort térmico y microambientales, caracterización de materiales, etc., actividades fundamentales para articular las dimensiones histórico-documental y científicotécnicas.
Como parte de este propósito, a más de estructurarse metodológicamente the Harris Matrix, se ha definido dentro de su estructura la característica material de las UEM, (Fig. 7) aspecto que permite identificar y relacionar históricamente parte de la tradición constructiva, la compatibilidad de los materiales, su manejo, capacidad de adaptación al lugar y durabilidad en el tiempo. En suma, recuperar sistemáticamente parte el reflejo de la enseñanza no reglada que es la base del legado patrimonial existente en la región.

\section{AGRADECIMIENTOS}

A Agustín por el tiempo desinteresado brindado al progreso de este trabajo. Al Taita Alejo, por la labor de conservar Shuracpamba. A Martín Alejandro y Edison.

\section{BIBLIOGRAFÍA}

Aguirre, M. y Álvarez, A. 2015: “Análisis histórico-constructivo de la iglesia de Santo Domingo de Guzmán (Pajarejos, Segovia) por medio del análisis estratigráfico constructivo". Maskana, 6 (1), pp. 131-148.

Arteaga, D. 2008: "Los artesanos de Cuenca entre 1557 y 1822". Cuenca. Ciudad Artesanal, s/n, pp. 29-50.

Altamirano, C. 2011: "Estudio y experimentación de paneles estructurales y de revestimiento en base de la caña de la Sierra". Tesis para la obtención título de Arquitecto. Universidad de Cuenca. Ecuador.

Azkárate, A. 2010: "El análisis estratigráfico en la restauración del patrimonio construido. Actas del congreso Arqueología aplicada al estudio e interpretación de edificios históricos”. En E. de Vega, C. Martín (dir.). Actas del congreso Arqueología aplicada al estudio e interpretación de edificios históricos. Últimas tendencias metodológicas, pp. 51-63. Ministerio de Cultura, Subdirección General Técnica de Publicaciones, Información y Documentación, Madrid, España.

Azkárate, A., Barreiro, D., Criado, F., García Camino, I., Gutiérrez Lloret, S., Quirós, J. A. y Salvatierra, V. 2009: "La Arqueología Hoy”. Actas del Congreso Medio Siglo de Arqueología en el Cantábrico Oriental y su Entorno, Vitoria-Gasteiz, pp. 599-615.

Brandi, C. 1988: "Teoría de la restauración”. Editorial Alianza, Madrid.

Brogiolo, G. 1995: “Arqueología estratigráfica y restauración”. Informes de la Construcción, 46 (435), pp. 31-36.

Bravo Díaz, A. 2013: "Cuando los saberes se hace audibles. La transmisión del conocimiento en el Ecuador en el siglo XXI." Tesis para la obtención del grado de Magíster en Antropología. Facultad Latinoamericana de Ciencias Sociales. Quito, Ecuador.

Caballero Zoreda, L. 1995: "Método para el análisis estratigráfico en construcciones históricas o Lectura de paramentos. Informes de la Construcción, 46(435), pp. 37-46.

Carrasco, I. 2002: "Shuracpamba, el peyote y el Fuego del Itzachilatán". Cáñamo: La revista de la cultura del cannabis, 53, pp. 102-106.

Carrasco, M. 2012: "El Paso: Una Hacienda Tradicional en la Sierra Centro - Sur del Ecuador". http://1239manuel.blogspot.com/, (consultado el 27/03/2016).

Chacón, J. 1977: "Libro Segundo de Cabildos de Cuenca. 1563 - 1569". Archivo Histórico del Guayas. Guayaquil, Ecuador.

Choay, F. 2007: “Alegoría del Patrimonio”. Gustavo Gilli, Barcelona.

Doglioni, F. 1997: “Stratigrafia e restauro”. Editorial Lint, Trieste. 
Harris, E. 1991: "Principios de Estratigrafia Arqueológica". Editorial Crítica, Barcelona.

Latorre, P. y Caballero, L. 1995: "La importancia del análisis estratigráfico en las construcciones históricas en el debate sobre la restauración monumental", Informes de la Construcción, 46(435), pp. 5-18.

Linares, A., Sáenz, J., Pérez P., Clemente, L. y Maganto, E. 2013: “La Sífilis (Bubas, mal francés, morbo gálico) como una enfermedad venérea de origen americano: Bibliografía española durante el período 1493-1550. (I) Introducción y diseminación por Europa". Actas del LXVIII Congreso Nacional de Urología, Granada. http://historia.aeu.es/abstractMurcia. asp?Codigo $=$ P114, (consultado el 01/04/2016).

Maldonado, D. 2009: "La Ruta del Cóndor". Trabajo de graduación previo a la obtención del título de Guía Superior de Turismo. Universidad del Azuay. Cuenca, Ecuador.

Marca, R. 2011: "El Qhapaq Ñan a su paso por el cerro Shunin en el cantón Oña". Trabajo de investigación previo a la obtención del título de Licenciado en la Especialidad de Historia y Geografia. Universidad de Cuenca. Cuenca, Ecuador.

Martínez, J. 1983: "La pintura popular del Carmen: identidad y cultura en el siglo XVIII", Centro Interamericano de Artesanías y Artes Populares. Cuenca, Ecuador.

Mileto, C. y Vegas, F. 2003: "El análisis estratigráfico constructivo como estudio previo al proyecto de restauración arquitectónica: metodología y aplicación". Arqueología de la Arquitectura, 2, pp. 189-196.

Mileto, C. y Vegas, F. 2010: "El análisis estratigráfico: una herramienta de conocimiento y conservación de la arquitectura". En E. de Vega, C. Martín (dir.). Actas del congreso Arqueología aplicada al estudio e interpretación de edificios históricos. Últimas tendencias metodológicas, pp. 145-158. Ministerio de Cultura, Subdirección General Técnica de Publicaciones, Información y Documentación, Madrid, España.

Moscoso, M. s/f. "La tipología de la Hacienda andina, el caso de Susudel Ecuador". En X Congreso sobre Turismo y Desarrollo y VI Simposisio Internacional Valor y Patrimonio Artístico y Cultural. www.eumed.net/ eve/10td-lki/pon/msmc.pdf (consultado el 07/10/2016)

Ortega, A. 2015: "Propuesta de implementación de la ciclo ruta Zhuracpamba, como atractivo turístico de la parroquia Susudel, cantón San Felipe de Oña, Provincia del Azuay". Trabajo de investigación previa a la obtención del título de Ingeniera en Turismo. Universidad de Cuenca. Cuenca, Ecuador.
Palomeque, S. 1990: "Cuenca en el siglo XIX. La articulación de una región”. Editorial ABYA-YALA. Quito, Ecuador. http://www.flacsoandes. edu.ec/libros/digital/44294.pdf, (consultado el 30/03/2016).

Parenti, R. 1988: "Le tecniche di documentazione per una lettura stratigrafica dell'elevato". En: Francovich, R., R. Parenti, Archeologia e restauro dei monumento, pp. 249-279. Universidad de Siena, Siena.

Parenti, R. 1995: "Historia, importancia y aplicaciones del método de lectura de paramentos". Informes de la Construcción, 46 (435), pp. 19-29.

Riegl, A. 1905: "El culto moderno de los monumentos. Caracteres y origen. La balsa de la medusa". Editorial Antonio Machado. Madrid.

Rolón, G. 2014: "Patrones arquitectónicos, clusters constructivos homogéneos y variabilidad en el estudio de edificios históricos. Aspectos técnico formales de la vivienda rural en la provincia de La Rioja (Argentina) durante el período republicano", Arqueología de la Arquitectura, 11, pp. 1-24. (consultado el 30/03/2016).

Rolón, G. y Rotondaro, R. 2010: "Empleo del método estratigráfico en el estudio de la vivienda rural vernácula construida con tierra: un caso de aplicación en La Rioja, Argentina", Arqueología de la Arquitectura, 7, pp. 213-222.

Sánchez Zufiaurre, L. 2004: "Un método de prospección en arqueología de la arquitectura. La arquitectura medieval invisible". Arqueología de la Arquitectura, 3, pp. 185-197.

Pérez Pimentel, R. (?): "Diccionario Bibliográfico del Ecuador": http:// www.diccionariobiograficoecuador.com/tomos/tomo13/v2.htm, (consultado el 28/03/2016).

Stacey, M. 2007: "Nudos de poder y familias encadenas de frontera", https://es.scribd.com/doc/25004192/Nudos-de-Poder-y-Familias-encadenadas-de-Frontera, (consultado el 28/03/2016).

Tabales Rodríguez, M. A. 2002: "Sistemas de análisis arqueológico de edificios históricos", Tesis para optar a título de Doctor. Universidad de Sevilla, Secretariado de Publicaciones, Sevilla, España.

Ullauri, G. 2014: "Rendición de Cuentas. 15 de mayo al 31 de diciembre de 2014. Oña, Ecuador", http://www.ona.gob.ec/index.php/rendicion-decuentas/rendicion-de-cuentas-2014, (consultado el 31/03/2016).

Valdivieso Pozo, A. 1991: Valdivieso: el valle, el apellido y la familia, Cuenca, Ecuador.

Valdivieso Pozo, A. 2016a: Entrevista realizada el día jueves 31 de marzo de 2016. Cuenca, Ecuador.

Valdivieso Pozo, A. 2016b: Entrevista realizada el día jueves 26 de abril de 2016. Cuenca, Ecuador. 